\title{
BreastCore
}

\section{Gynecomastia - Conservative and Surgical Management}

\author{
Kristin Baumann \\ Clinic for Gynecology and Obstetrics, University Medical Centre Schleswig-Holstein Campus Lübeck, Lübeck, Germany
}

\section{Keywords}

Gynecomastia - Male breast tissue .

Pseudogynecomastia

\section{Summary}

Gynecomastia is defined as a unilateral or bilateral persistent benign mammary gland enlargement in men. Prevalence of asymptomatic gynecomastia is up to $65 \%$. True gynecomastia must be distinguished from pseudogynecomastia. Typically, in true gynecomastia, a solid tissue mass is palpable below the nipple-areolar complex. Malignant changes such as male mammary carcinoma must always be ruled out. The causes of gynecomastia are diverse. An imbalance of female to male hormones triggers the onset of the disease. This imbalance can be caused by endogenous diseases like hyperthyroidism, chronic liver disease, primary or secondary gonadal failure, androgen resistance syndromes, medication, and drug abuse. A series of heart or hypertension medications can also trigger gynecomastia. A basic requirement of proper therapy planning is knowledge of the triggers and possible drug therapy options. Inquiring about the patient's lifestyle and medication history is essential. Drug therapy with tamoxifen may be considered at an early stage. For gynecomastia persisting over 12 months, surgical excision is the treatment of choice, and there are several surgical options available depending on the grade of the gynecomastia. A thoughtful approach to managing this condition can lead to high patient satisfaction.

(C) 2018 S. Karger GmbH, Freiburg

\section{Introduction}

A supernatant of male mammary tissue is a common finding and appears uni- or bilaterally in $32-65 \%$ of all men $[1-3,5]$ (fig. 1-4). The term gynecomastia originates from the Greek words gyne (women) and mastos (breast) and describes a feminization of the male breast [4]. True gynecomastia is caused by a proliferation of the mammary glands with emerging dense subareolar glandular tissue [5] and must be distinguished from pseudogynecomastia due to fat deposits in obesity. The classification of gynecomastia is based on clinical examination measuring the volume und degree of ptosis of the glandular tissue [6] (table 1). In most cases, gynecomastia is asymptomatic; however, it can be associated with pain and tenderness of the mammary gland. Psychologic impairments due to a disturbed body image are common and especially affect adolescents [7].

\section{Etiology}

The causes of gynecomastia are multifactorial, and $25 \%$ of all cases appear idiopathically. Among the underlying causes, 3 groups of triggers are distinguished: physiologic, pathologic and pharmacologic/toxic. Pathophysiologically, female hormone imbalance has been shown to trigger glandular growth. This imbalance may in turn also be of pathologic or physiologic/idiopathic origin. There is strong evidence for the stimulating effect of estrogen on breast tissue development. Any disorder or medication leading to female hormone imbalance can trigger gynecomastia. Endogenous diseases like hyperthyroidism, chronic liver disease, primary or secondary gonadal failure, androgen resistance syndromes, medication, and lifestyle factors like drug abuse represent typical causes of gynecomastia [8] (table 2). In most cases, gynecomastia is caused by shortterm hormonal fluctuations that limit themselves physiologically, which can occur neonatally, during puberty, and in elderly men. In the neonatal period, a preliminary physiologic bilateral mammary glandular swelling is triggered by maternal placental estrogens and resolves within a few weeks after birth. In adolescence, physiologic pubertal gynecomastia can develop and may last up to 6 months. This is triggered by a relative estrogen excess, mainly due to peripheral aromatization of the testicular and adrenal androgens. Testicular testosterone production increases in late puberty and leads to a spontaneous regression of the gynecomastia [9]. Due to a decrease in testosterone production and an increase in sex hormone-binding globulin, gynecomastia is also common in elderly men.

\section{KARGER}

(c) 2018 S. Karger GmbH, Freiburg

Fax +497614520714 
Fig. 1. Gynecomastia preoperative, frontal.

Fig. 2. Gynecomastia preoperative, side view right.

\section{1}

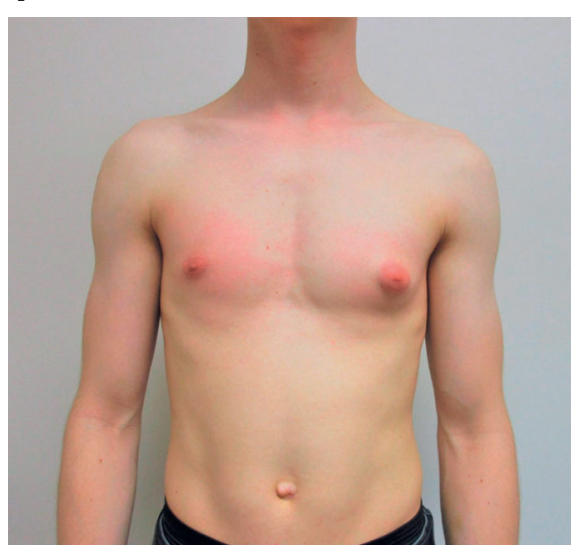

3

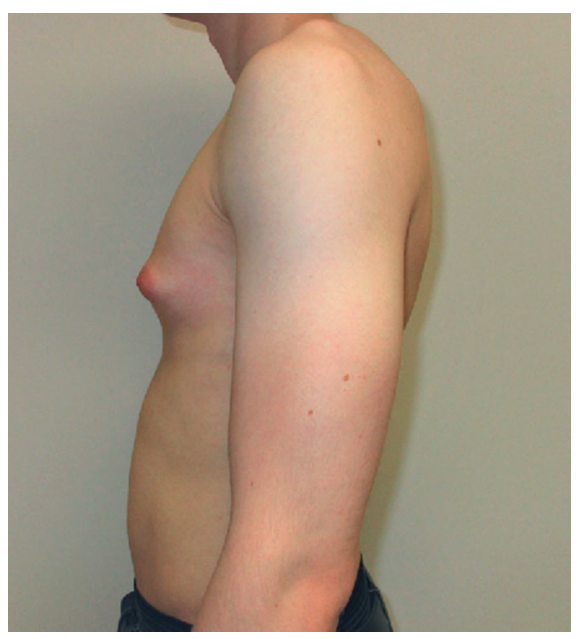

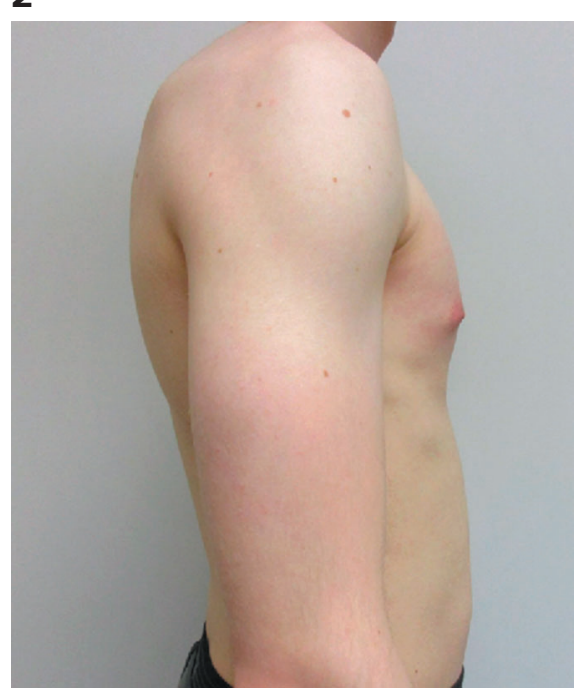

4

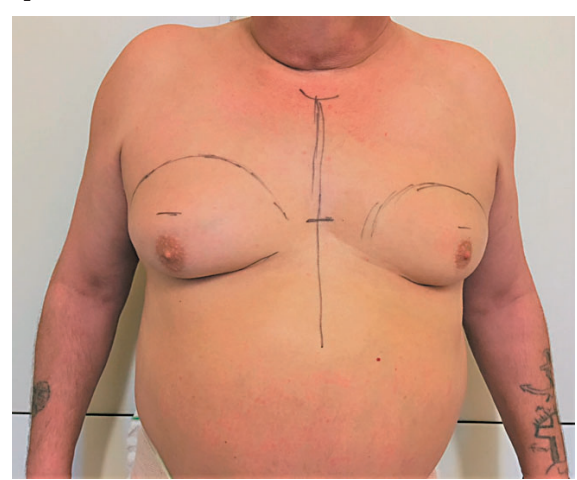

Fig. 3. Gynecomastia preoperative, side view left.

Fig. 4. Gynecomastia, frontal.

\section{Diagnosis}

The first step in the diagnosis of gynecomastia is to differentiate between pseudogynecomastia and true gynecomastia. In the case of true gynecomastia, clinical examination by palpation followed by ultrasound examination (fig. 5) and if necessary mammography (fig. 6) reveal glandular tissue. Palpation of the breast should already be able to clinically distinguish fatty tissue from glandular tissue and should include a more detailed assessment of the breast such as ptosis, skin excess, and nipple retraction. The physical examination should also extend to testicular palpation in order to detect testicular changes and atrophies at an early stage and to pave the way for further diagnostic measures. In particular, in young men with a negative history and bilateral gynecomastia, the incidence of testicular endocrine tumors is showing a significant increase [10].

The diagnosis of gynecomastia must be confirmed histologically by a sonographically correlated core biopsy to exclude malignancy (fig. 7), showing a 90\% sensitivity and specificity [11]. A careful his- 


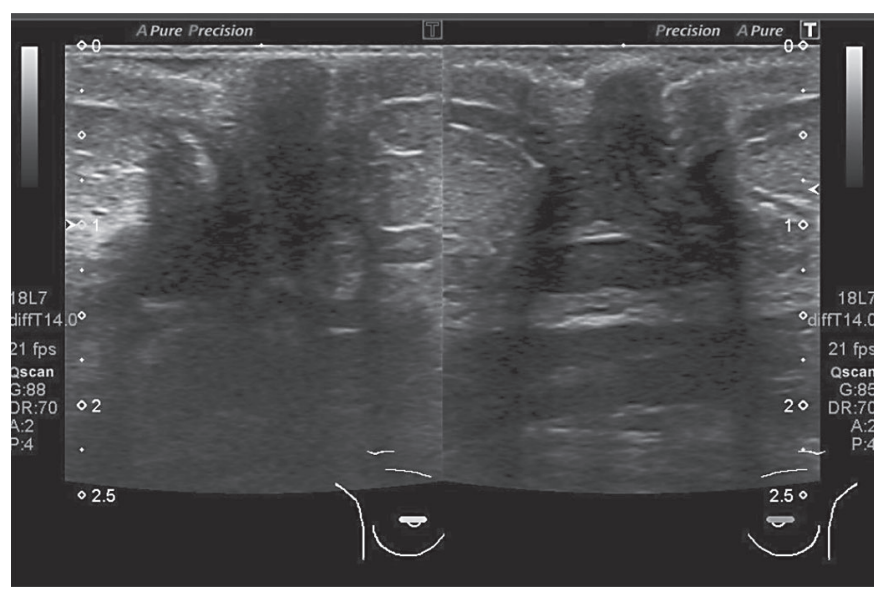

Fig. 5. Breast sonography on both sides.

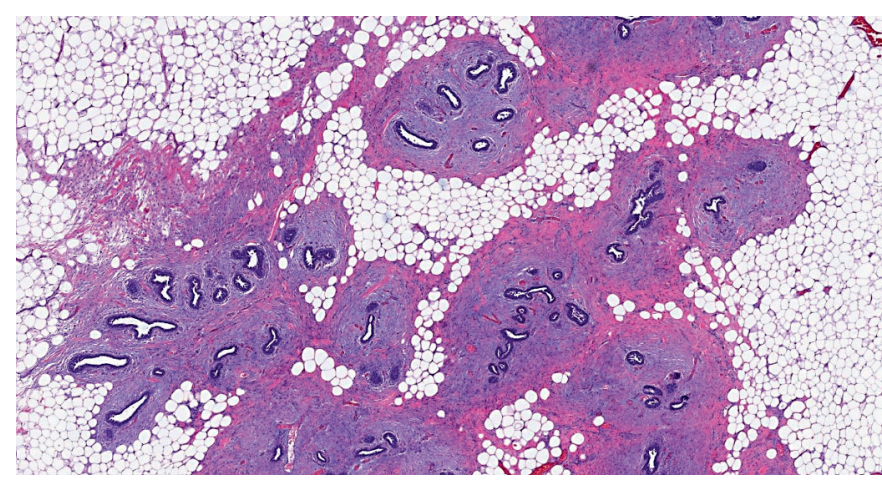

Fig. 7. Hematoxylin/eosin, $\times 2$; increased glandular elements are embedded in a cell-rich, partly edematous loose stroma and surrounded by abundant fatty tissue.

tory, especially with regard to lifestyle habits, drugs, and medications, is indispensable for the diagnosis. Recent changes, for example commencement of antihypertensive drug therapy, should be inquired about. Standard diagnostics include laboratory tests like human choric gonadotropin, luteinizing hormone, thyroid-stimulating hormone, testosterone, and estradiol [12]. Due to the circadian rhythm of hormone secretion, laboratory monitoring must be performed in the morning at the time of maximum hormone release [13].

\section{Conservative and Surgical Management}

Depending on the underlying cause, the therapy of gynecomastia may be conservative or surgical. Self-limiting physiologic forms of gynecomastia should be followed up until resolved. In the case of persistence or progress, if necessary, laboratory diagnostic tests should be repeated to detect hormonal processes as quickly as possible. Conservative therapy must be based on the cause of the gynecomastia.

Gynecomastia - Conservative and Surgical
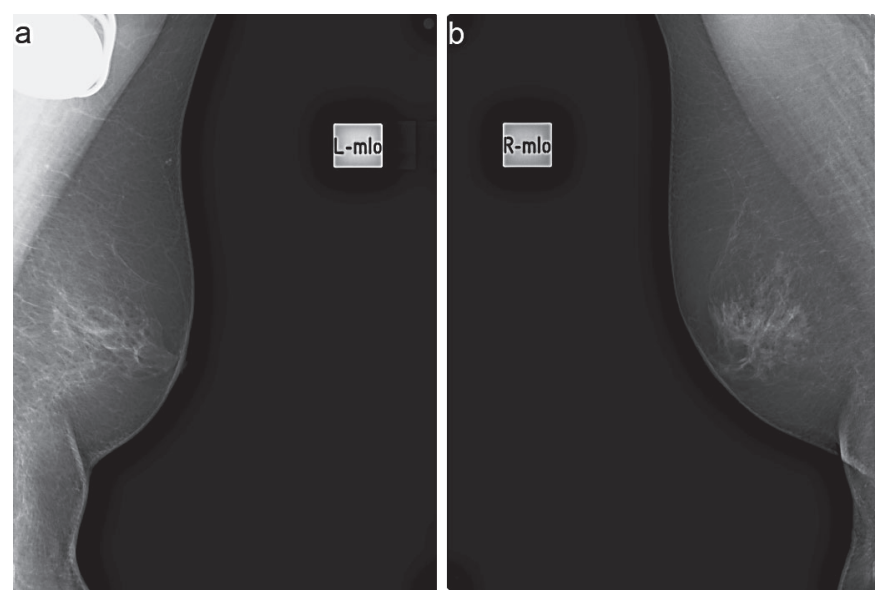

Fig. 6. Mammography, MLO.

Table 2. Causes of gynecomastia $[3,6,8]$

\begin{tabular}{|c|c|}
\hline Physiologic & $\begin{array}{l}\text { neonatal } \\
\text { adolescent } \\
\text { aging-related }\end{array}$ \\
\hline Drug-induced & $\begin{array}{l}\text { antihypertensive agents } \\
\text { antibiotics } \\
\text { hormones } \\
\text { drugs } \\
\text { gastrointestinal agents } \\
\text { antiandrogens }\end{array}$ \\
\hline Decreased androgens & $\begin{array}{l}\text { primary (testicular) hypogonadism } \\
\text { secondary (central) hypogonadism } \\
\text { androgen insensitivity syndrome } \\
5 \alpha \text {-reductase deficiency } \\
17 \beta \text {-hydroxysteroid dehydrogenase deficiency } \\
\text { Klinefelter syndrome }\end{array}$ \\
\hline Increased estrogens & $\begin{array}{l}\text { adrenal/testis tumor } \\
\text { testicular tumor } \\
\text { human chorionic gonadotropin-secreting tumor } \\
\text { familial aromatase excess syndrome } \\
\text { (obesity) }\end{array}$ \\
\hline Other & $\begin{array}{l}\text { malnutrition } \\
\text { cystic fibrosis } \\
\text { alcoholism } \\
\text { psychologic stress } \\
\text { myotonic dystrophy } \\
\text { herpes zoster infection }\end{array}$ \\
\hline
\end{tabular}

If hypogonadism is present, symptomatic therapy with testosterone is recommended.

In the case of medically induced gynecomastia, discontinuation of the drug or conversion to a different medication should be considered; however, it is not always possible to change or discontinue medication in these cases. While many antihypertensive medications lead to gynecomastia as a side effect, spironolactone has the 


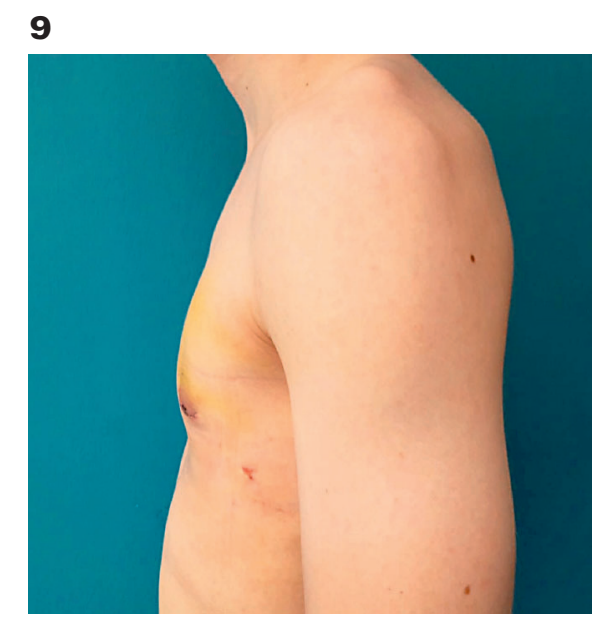

Fig. 8. Gynecomastia postoperative, periareolar subcutaneous mastectomy, frontal.

Fig. 9. Gynecomastia postoperative, periareolar subcutaneous mastectomy, side view left.

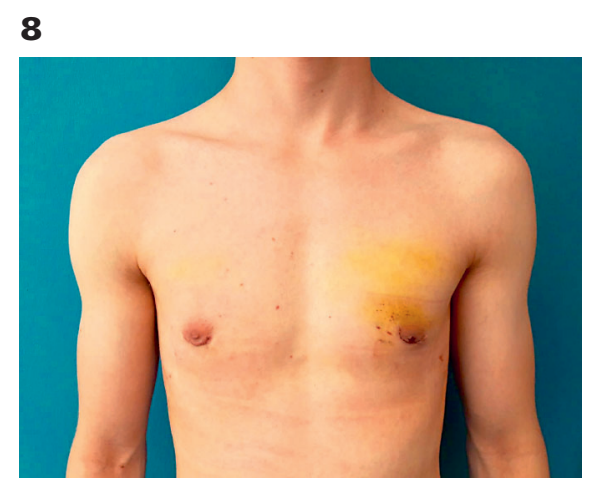

10

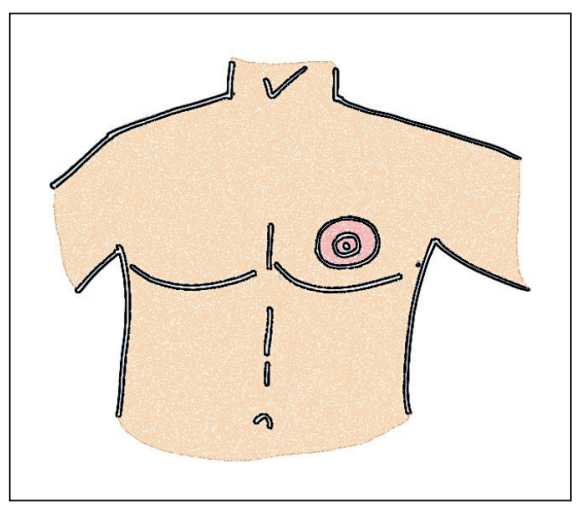

11

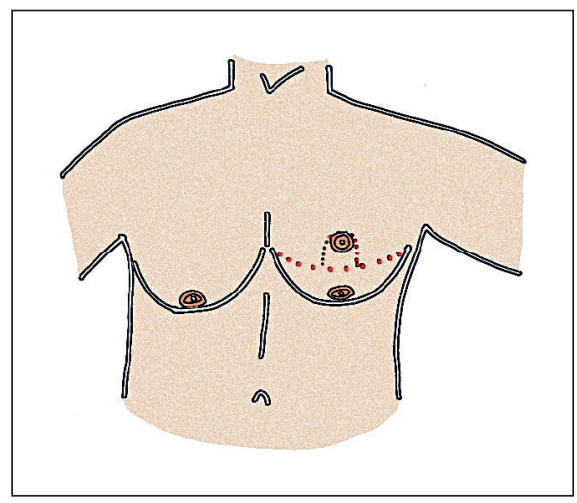

Fig. 10. Operative procedure according to Benelli [25].

Fig. 11. Operative procedure according to Kornstein [26].

and post-traumatic deep vein thrombosis, are rarely reported [18]. The use of anastrozole, an aromatase inhibitor, is not recommended as it did not show more effectiveness than placebo in boys with pubertal gynecomastia [19].

Prostate cancer patients represent a special group receiving antiandrogenic therapies with a high risk of iatrogenic gynecomastia. Tamoxifen or even radiotherapy can reduce gynecomastia in these patients [20, 21].

Low-dose irradiation mostly in single fractions (12-15 Gy) could be used as prophylaxis to decrease the risk of antiandrogeninduced gynecomastia [22].

If conservative pharmacologic therapy attempts are to be considered, it should be noted that hypertrophic glandular tissue becomes irreversibly fibrotic by way of remodeling after no more than 12 months. This fibrous tissue cannot be removed conservatively and proceeding with surgical management must be considered [23].

The indication for surgical therapy is based on the patient's suffering, including psychosocial stress and pain as well as cosmetic distortion [24]. The aim of all surgical procedures is to remove the hypertrophic fibrotic glandular tissue and to reestablish the male breast shape. Therapeutic techniques include breast tissue resection, liposuction, and combined techniques. From stage III onwards, reduction mammoplasty should be explored taking into 
Fig. 12. Algorithm for the evaluation and treatment of gynecomastia (modified from $[6,11,28$, 30]).

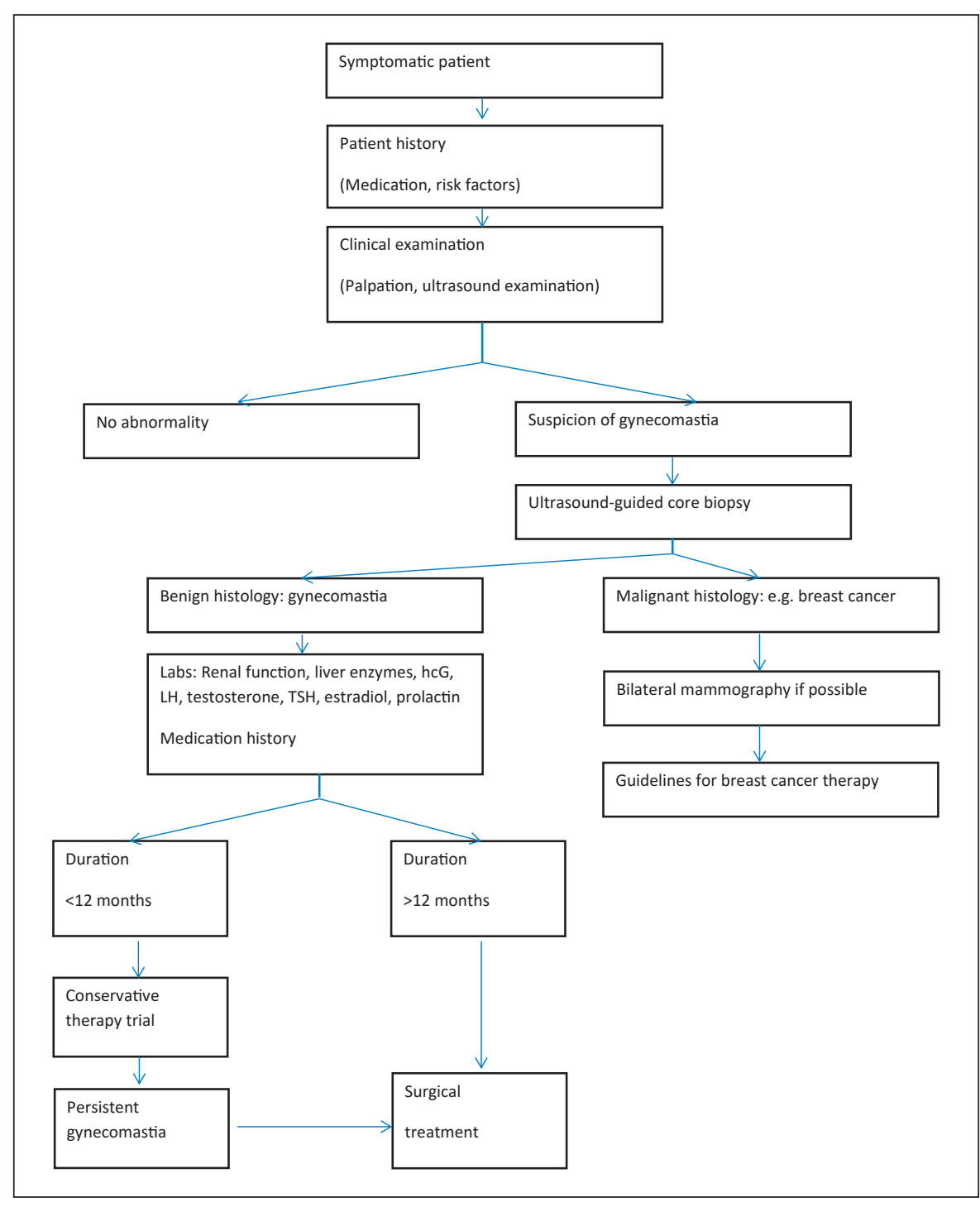

consideration the extent of the hypertrophic tissue and the expertise of the surgeon (table 3) [25]. For milder forms, the periareolar edge cut to the mastectomy can suffice (figs. 8, 9). In the case of surplus skin, the skin envelope should be reduced using techniques such as the skin reduction procedure developed by Benelli [26] (fig. 10) or mastectomy with repositioning of the nipple developed by Kornstein [27] (fig. 11). Since open surgical procedures can produce unsightly scarring, a scar-reducing technique was developed by Bailey et al. [28]. Liposuction is used with a 'pull-through' technique to remove the glandular tissue without additional incision; using a Kocher clamp, the tissue is grasped and pulled out [29].
Excess skin is the limiting factor for this technique. Due to the weak data, no recommendation can be made with regard to the best surgical approach [30].

Overall, good preoperative planning leads to good cosmetic results with high patient satisfaction and low complication rates (fig. 12).

\section{Disclosure Statement}

The author has no conflict of interest. 


\section{References}

1 Narula HS, Carlson HE: Gynaecomastia - pathophysiology, diagnosis and treatment. Nat Rev Endocrinol 2014;10:684-698.

2 Lanitis S, Starren E, Read J: Surgical management of gynaecomastia: outcomes from our experience. Breast 2008;17:596-603.

3 Braunstein G: Gynecomastia. N Engl J Med 2007;357: 1229-1237.

4 Diamantopoulos S, Bao Y: Gynecomastia and premature thelarche: a guide for practitioners. Pediatr Rev 2007;28:e57-68.

$\checkmark 5$ Ladizinski B, Lee KC, Nutan FN, Higgins HW 2nd, Federman DG: Gynecomastia: etiologies, clinical presentations, diagnosis, and management. South Med J 2014;107:44-49.

6 Rohrich RJ, Ha RY, Kenkel JM, Adams WP Jr: Classification and management of gynecomastia: defining the role of ultrasound-assisted liposuction. Plast Reconstr Surg 2003;111:909-923; discussion 924-925.

7 Rew L, Young C, Harrison T, Caridi R: A systematic review of literature on psychosocial aspects of gynecomastia in adolescents and young men. J Adolesc 2015; 43:206-212.

8 Johnson RE, Murad MH: Gynecomastia: phathophysiology, evaluation, and management. Mayo Clin Proc 2009;84:1010-1015.

9 Nordt C, Divanta A: Gynecomastia in adolescents. Curr Opin Pediatr 2008;20:375-382.

10 Bowers SP, Pearlman NW, McIntyre RC Jr, Finlayson CA, Huerd S: Cost-effective management of gynecomastia. Am J Surg 1998;176:638-641.

11 Morcos RN, Kizy T: Gynecomastia. When is treatment indicated? J Fam Pract 2012;61:719-725.
Evans GF, Anthony T, Turnage RH, et al: The diagnostic accuracy of mammography in the evaluation of male breast disease. Am J Surg 2001;181:96-100.

13 Baumann K, Pursche T: Congenital and developmental abnormalities of the breast; in Jatoi I, Rody A (eds): Management of Breast Diseases. Basel, Springer, 2016, pp 41-55.

14 Mosenkis A, Townsend RR: Gynecomastia and antihypertensive therapy. J Clin Hypertens (Greenwich) 2004;6469-6470.

15 Pitt B, Remme W, Zannad F, et al.; Eplerenone PostAcute Myocardial Infarction Heart Failure Efficacy and Survival Study Investigators: Eplerenone, a selective aldosterone blocker, in patients with left ventricular dysfunction after myocardial infarction. N Engl J Med 2003;348:1309-1321.

16 Hanavadi S, Banerjee D, Monypenny IJ, Mansel RE: The role of tamoxifen in the management of gynaecomastia. Breast 2006;15:276-280.

17 Johnson RE, Kermott CA, Murad MH: Gynecomastia - evaluation and current treatment options. Ther Clin Risk Manag 2011;7:145-148.

18 Ting ACW, Chow LWC, Leung YF: Comparison of tamoxifen with danazol in the management of idiopathic gynecomastia. Am Surg 2000;66:38-40.

19 Plourde PV, Reiter EO, Jou HC, et al: Safety and efficacy of anastrozole for the treatment of pubertal gynecomastia: a randomized,double-blind, placebo-controlled trial. J Clin Endocrinol Metab. 2004;89:44284433.

20 Di Lorenzo G1, Autorino R, Perdonà S, De Placido S: Management of gynaecomastia in patients with prostate cancer: a systematic review. Lancet Oncol 2005;6: 972-979.
1 Autorino R, Perdonà S, D'Armiento $\mathrm{M}, \mathrm{De}$ Sio $\mathrm{M}, \mathrm{Da}$ miano R, Cosentino L, Di Lorenzo G: Gynecomastia in patients with prostate cancer: update on treatment options. Prostate Cancer Prostatic Dis 2006;9:109-114.

22 Widmark A, Fossa SD, Lundmo P, et al: Does prophylactic breast irradiation prevent antiandrogen-induced gynecomastia? Evaluation of 253 patients in the randomized Scandinavian trial SPCG-7/SFUO-3. Urology 2003;61:145-151.

23 Bannayan GA, Hajdu SI: Gynecomastia: clinicopathologic study of 351 cases. Am J Clin Pathol 1972;57: 431-437.

24 Ordaz DL, Thompson JK: Gynecomastia and psychological functioning: a review of the literature. Body Image 2015;15:141-148.

25 Wolter A, Scholz T, Diedrichson J, Liebau J: Surgical treatment of gynecomastia: an algorithm (Article in German). Handchir Mikrochir Plast Chir 2013;45:7379.

26 Benelli L: A new periareolar mammaplasty: the 'round block' technique. Aesthetic Plast Surg 1990;14:93-100.

27 Kornstein AN, Cinelli PB: Inferior pedicle reduction technique for larger forms of gynecomastia. Aesthetic Plast Surg 1992;16:331-335.

28 Fentiman IS: Managing male mammary maladies. Eur J Breast Health 20181;14:5-9.

29 Bailey SH, Guenther D, Constantine F, Rohrich RJ: Gynecomastia management: an evolution and refinement in technique at UT Southwestern Medical Center. Plast Reconstr Surg Glob Open 2016;4:e734.

30 Fagerlund A, Lewin R, Rufolo G, et al: Gynecomastia: a systematic review. J Plast Surg Hand Surg 2015;49: 311-318. 